\title{
Políticas Públicas para a Educação Superior no Brasil (1990-2020): da Universidade Operacional ao Programa FUTURE-SE (uma reforma em andamento)
}

\author{
Mário Luiz Neves de Azevedo
}

Professor titular na Universidade Estadual de Maringá (UEM). Pesquisador do CNPq.

\author{
Afrânio Mendes Catani
}

Professor titular na-Universidade de São Paulo (USP), e professor convidado na Universidade Federal Fluminense (UFF). Pesquisador do CNPq.

Resumo

Trata-se de um ensaio analítico sobre políticas públicas para a Educação Superior no Brasil desde os anos 1990 até 2020. Metodologicamente, tendo por base a teoria dos campos sociais de Pierre Bourdieu, esta análise considera que os diversos sistemas de Educação Superior no Brasil (federais e estaduais) constituem um campo social (campo acadêmico) que está sendo transformado em sentido gerencial e em favor do mercado.

Palavras chave: Educação Superior, Políticas Públicas, Brasil, Universidade Operacional, FUTURE-SE. 
Políticas Públicas para la Educación Superior en Brasil (1990-2020): de la universidad operacional al programa FUTURE-SE (una reforma en curso)

\title{
Resumen
}

Este ensayo analiza políticas públicas para la educación superior en Brasil desde la década de 1990 hasta los años 2020. Metodológicamente, basado en la teoría de los campos sociales de Pierre Bourdieu, este análisis considera que los diversos sistemas de educación superior en Brasil (federal y estatal) constituyen un campo social (campo académico) que se está transformando en un sentido gerencial y a favor del mercado.

Palabras clave: Educación Superior; Políticas públicas; Brasil; Universidad operacional; FUTURE-SE.

Public Policies for Higher Education in Brazil (1990-2020): from operational university to the FUTURE-SE Program (A Reform in Progress)

\begin{abstract}
This is an analytical essay on public policies for higher education in Brazil from the 1990s to 2020. Methodologically, based on Pierre Bourdieu's theory of social fields, this research considers that the higher education systems in Brazil (federal and state) constitute a social field (academic field) that is being transformed in a managerial sense and in favor of the market.
\end{abstract}

Keywords: higher education, public policies, Brazil, operational university, FUTURE-SE. 


\section{Introdução}

Este texto é uma análise das políticas públicas na Educação Superior, remetendo seus efeitos à sociedade como um todo e, especialmente, aos atores sociais atuantes no campo acadêmico. Dessa forma, metodologicamente, partimos do pressuposto de que os diversos sistemas de Educação Superior no Brasil (o Sistema Federal de Educação, que inclui os estabelecimentos privados de Educação Superior de todo Brasil, e 26 sistemas estaduais de educação mais o Distrito Federal) constituem um campo social, o campo acadêmico brasileiro. O que significa dizer que o conjunto das universidades nacionais (federais, estaduais, municipais e privadas), enquanto campo social, é um espaço estruturado de posições em que os atores sociais travam relações, fazem alianças e lutam entre si (Bourdieu, 2004), bem como se relacionam com atores externos que, apesar da autonomia universitária, são capazes de interferir no contexto da influência (Ball \& Bowe, 1992), e no arranjo espacial desse mesmo campo.

É assim que deve-se ter em conta que o meta-ator no campo universitário, aliás, em todos os campos sociais destinatários de políticas públicas, é o Estado. Como meta-ator, o Estado é promotor, organizador e executor de políticas públicas. O Estado é ao mesmo tempo um meta-ator e um "meta-campo social" (Bourdieu, 1996), aliás de ser coerente com o conceito de "Estado Amplo" de Gramsci (1999).

Portanto, para se analisar as políticas públicas, deve-se ter a clareza de que o Estado não é algo homogêneo, senão que é, na realidade, um campo de contradições e lutas. O Estado, figurativamente, é um vasto cadinho em que diferentes atores sociais, e diversos tipos de capital (político, econômico, social, cultural, simbólico, acadêmico, etc.), procuram a representação e a valorização. Parafraseando Bourdieu (1996), o Estado, como um Banco Central de capitais, exerce uma sorte de arbitragem nas taxas de câmbio entre diferentes e específicos tipos capital. Por isso, o Estado, ao operar políticas públicas, influencia o arranjo espacial ocupado pelos atores sociais nos campos sociais correspondentes, reestruturando o zoneamento geográfico (localização), distribuindo valores (de todas as espécies e tipos), e arbitrando a luta de interesses e a taxa de câmbios entre distintos e distintivos capitais.

Ademais, para se compreender a reforma em andamento na Educação Superior no Brasil, deve-se estar atento a que a ação de Estado se distingue entre policy (política pública como programa de ação), e politics (política em geral) (Muller, 2006), e que "a análise de políticas públicas está na encruzilhada das áreas de saber já estabelecidas, a partir das quais tomam emprestados seus principais conceitos" (Muller, 2006, p. 3).

\section{Políticas Públicas para a Educação Superior no Brasil (1990-2020)}

A Reforma Gerencialista da Educação Superior, desde a década de 1990, vem ocorrendo juntamente com a Reforma de Estado no Brasil, e com a adoção de uma política econômica que prioriza o livre jogo do mercado. A 
economia política dominante desde o Governo Collor de Mello (eleito em 1989), carrega a marca gerencialista e de mercadorização, afetando também o campo da Educação Superior. De acordo com Azevedo (2020), o Brasil, desde a década de 1990, tem passado por quatro gerações de reformas:

$1^{\text {a }}$ Geração de Reformas: transformação da Universidade Institucional em Universidade Operacional (1990-1998);

$2^{\text {a }}$. Geração de Reformas: ajuste organizacional da universidade (1998-2006); $3^{\text {a }}$. Geração de Reformas: internacionalização e transnacionalização da Educação Superior (2007-2012);

$4^{\text {a }}$. Geração de Reformas: benchmarking e universidade de plataforma (2012-atualidade) (p. 1-2).

Este encadeamento de reformas, inaugurado com a transformação da Universidade Institucional em "Universidade Operacional" (Chauí, 2003, p. 9), tem se referenciado em políticas identificadas com o neoliberalismo. Os reformadores, mesmo que a universidade forneça um bem público e social, procuram mercadorizar, privatizar ou transformar a universidade pública em um setor não exclusivo do Estado.

Em governos pós-2016, como o de Michel Temer (2016-2018), o Novo Regime Fiscal (NRF), e o de Jair Bolsonaro com o Programa FUTURE-SE, a tônica tem residido no corte orçamentário, abrindo espaços para o provisionamento de Educação Superior por empresas provedoras de formação profissional em nível terciário. Para a consecução desse propósito, tem-se promovido uma espécie de transmutação da natureza pública da universidade (Catani; Oliveira, 2002; Silva Jr.; Sguissardi, 1999, Azevedo, 2016a e 2020).

Como se apresenta a situação da Educação Superior no Brasil na contemporaneidade? Entre outras características, ainda é baixa a cobertura da Educação Superior. Segundo o Censo da Educação 2018, elaborado pelo Instituto Nacional de Estudos e Pesquisas Educacionais (INEP), a taxa líquida de cobertura da Educação Superior no Brasil, para a população de 18 a 24 anos, é de 21,7\%. Em números absolutos, havia, no Brasil, em 2018, 8.450.755 alunos matriculados, sendo 6.394.244 em cursos presenciais e 2.056.511 estudantes em ensino a distância. Vale notar que as matrículas em IEs públicas, no mesmo ano, eram de 2.077 .481 (24,6\% do total). Já em IES privadas, frequentavam 6.373.274 $(75,4 \%)$ estudantes, indicando a continuidade do caráter privatista da oferta de Educação Superior no Brasil.

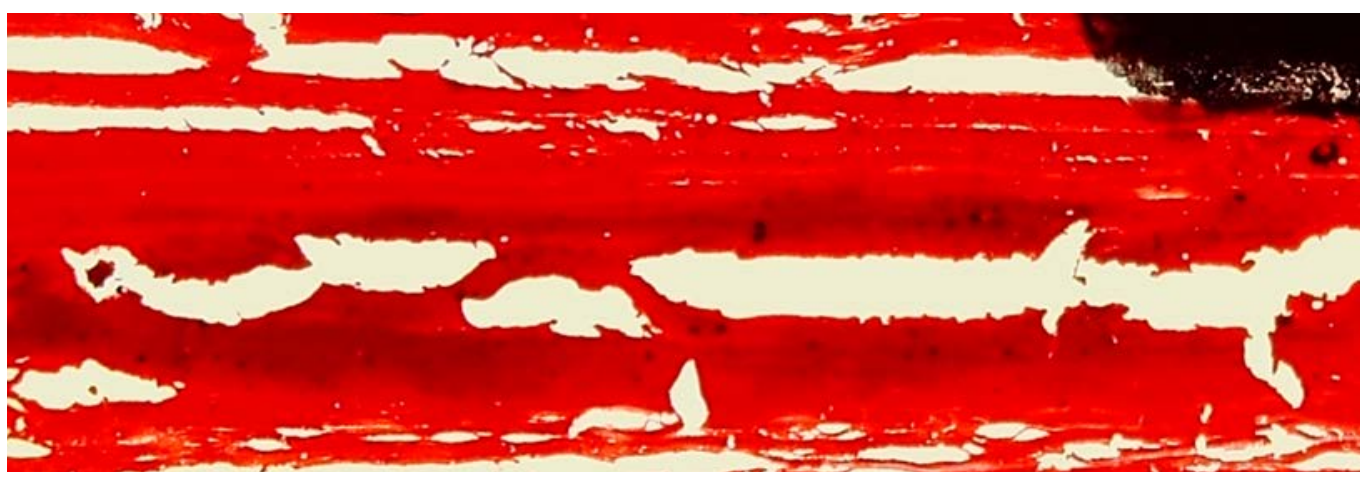


Figura 2. Matrículas, em cursos de graduação, por turno. Brasil 2008-2018

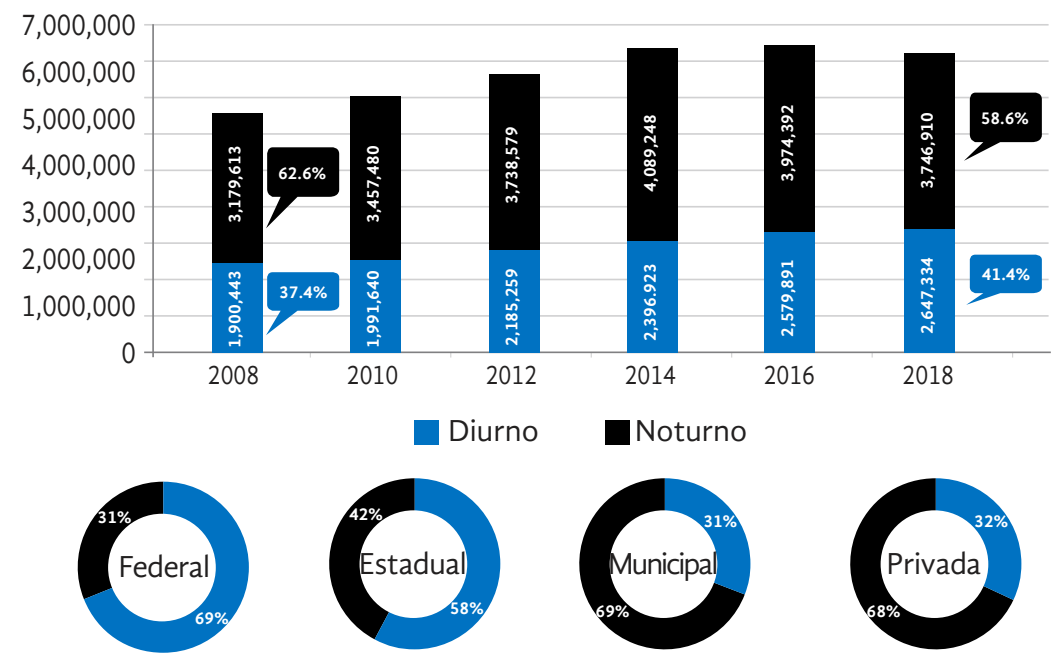

Fonte: Censo da Educação Superior 2018 (MEC-INEP).

Em geral, são as IES públicas estaduais (superiores a 40\%), e as municipais (próximas de 70\%), as que apresentam maior oferta de vagas no periodo noturno. Assim, a ocupação noturna de espaços ociosos em estabelecimentos públicos seria uma sensível oportunidade de oferecer Educação Superior gratuita, especialmente para os trabalhadores-estudantes impossibilitados de frequentar cursos de graduação (e de pós-graduação) diurnos e integrais. Entretanto, tal política de aumento de vagas públicas noturnas poderia contrariar os interesses de grupos empresariais (nacionais e estrangeiros) proprietários de IES privadas, que têm seu nicho de mercado (2/3 do total) no periodo noturno, visando atingir o trabalhador-estudante que tem buscado, pela carência de oferta pública, sua formação em nível superior na iniciativa privada ${ }^{3}$.

\section{$\mathrm{Da}$ "Universidade Operacional" ao "FUTURE-SE" (passando pelas políticas de Lula, Rousseff e Temer)}

As universidades brasileiras, no sentido jurídico, ainda não foram transformadas em organizações. Porém, paradoxalmente, mesmo com a preservação (aparente) da autonomia, vem incorporando o novo espírito organizacional, atendendo ao chamado dos governos reformistas de plantão, abandonando os traços do que é uma instituição social, e incorporando as características da chamada Universidade Operacional (Chauí, 2003).

A Universidade Operacional no Brasil está se efetivando há algum tempo. Desde o governo de Fernando Collor de Mello, com os ministros da Educação Carlos Chiarelli (1990-1991) e José Goldemberg (1991-1992), tentou-se mudar o modelo de universidade brasileira, cujo efetivo marco histórico da transformação parece estar no governo de Fernando Henrique 
Cardoso - FHC (1995-2002) ${ }^{4}$, mas que, vale ressaltar, não sofreu a significativa solução de continuidade nos governos de Luiz Inácio Lula da Silva (2003-2010). ${ }^{5}$

As características dessa "metamorfose" na Educação Superior brasileira, como perceberam Catani e Oliveira (2002), que afastaram significativamente às universidades das clássicas marcas de instituição, e aproximou-as dos contornos conceituais próprios de uma organização, podem ser assim elencadas:

1) o produtivismo acadêmico;

2) a busca de fontes alternativas de financiamento;

3) o atendimento das demandas do empresariado local/regional/nacional;

4) a preocupação (correta) de atender as demandas sociais (responsabilidade social);

5) a incessante tentativa de identificar as necessidades do "mercado de trabalho";

6) a diversificação e diferenciação universitárias (criação dos centros universitários, institutos, mestrados profissionalizantes, cursos sequenciais);

7) a Avaliação Institucional;

8) o ENEM - Exame Nacional do Ensino Médio (possível instrumento de classificação para acesso à Educação Superior);

9) a busca de nova matriz de distribuição de recursos para as universidades (número de alunos, cursos noturnos, outros "produtos");

10) crédito educativo (mercado de capitais).

Essas medidas foram efetivadas em uma especial conjuntura de disputa política no Brasil, a exemplo das eleições presidenciais para a sucessão do presidente José Sarney (1985-1990), cujo vencedor foi Fernando Collor de Mello (1990-1992), no processo de elaboração da Constituição da República, promulgada em 1988, e no debate que se iniciava em torno da Lei de Diretrizes e Bases da Educação Nacional (LDB - LEI No 9.394/1996). Ao mesmo tempo, a conjuntura política internacional demonstrava que uma nova direita estava em ascensão nos Estados Unidos com Ronald Reagan (1981-1989), e na Inglaterra com Margareth Thatcher (1979-1990).

A transição de governo, de FHC para Lula da Silva (2003-2010), no que se refere à política econômica, principalmente em seu primeiro mandato (2003-2006), não significou mudanças substanciais. Ao contrário, o governo de Lula parece que foi montado sobre uma estrutura de movimento inercial. Algo ("malditamente") herdado e, paradoxalmente, assumido e legitimado pela equipe do primeiro governo de Lula.

As políticas de Lula para a Educação Superior continham, por um lado, traços de continuidade em relação ao que vigia o ministro da Educação Paulo Renato Souza (1995-2002), e, por outro, apresentavam diferenças. Pontualmente, a proposta de reforma do Governo Lula, elaborada a partir dos princípios presentes no Documento II do MEC, e sintetizada na terceira versão do Anteprojeto de Lei do 29 de julho de 2005, e em sua quarta versão na forma de Projeto de Lei (PL n ${ }^{\circ}$. 7200/2006) do 12 de junho de 2006, enviada ao Congresso Nacional para análise e deliberação (porém ainda sem aprovação do Congresso Nacional), tinha os seguintes eixos: ${ }^{6}$ 
- definição de um modelo de financiamento universitário;

- regulação da transnacionalização (venda de participação acionária para grupos estrangeiros) de IEs privadas (30\% do capital);

- institucionalização da política de cotas para estudantes de escolas públicas, negros e índios;

- criação, nas universidades públicas e privadas, de um Conselho, com a participação da comunidade, os sindicatos, docentes e funcionários;

- controle na criação de novas universidades, devendo, para receber a denominação de "universidade", existir, no mínimo, doze cursos de graduação, em pelo menos três campos de saber, com avaliação positiva do MEC;

- submissão das universidades ao princípio da responsabilidade social, o que significa um compromisso das IES com as demandas sociais locais/ regionais;

- regulação das fundações de pesquisa;

- avaliação e credenciamento das IES com vistas a assegurar a qualidade.

No mundo do capital, necessariamente, as políticas públicas recebem um revestimento ideológico. Em época de liberalismo ortodoxo, como nos governos de Fernando Collor de Mello e Fernando Henrique Cardoso, as políticas públicas estavam compromissadas com a mercadorização de serviços públicos. Todavia no governo de Lula, a ideologia de mercado foi mitigada, e a preocupação social recebeu atenção de políticas focalizadas. Sem fazer nenhum juízo de valor, as políticas de inclusão na Educação Superior, promovidas pelo Programa Universidade para Todos (PROUNI - Lei $\mathrm{n}^{\mathrm{o}}$ 11.096/2005), para as matrículas em Instituições de Educação Superior (IES) privadas, e no Fundo de Financiamento Estudantil (FIES - Lei ${ }^{\circ}$ 10.260/2001), programa federal feito para, a sua vez, financiar a graduação em IES particulares, preteriram políticas públicas de universalização da Educação Superior em IES públicas.

No contexto de influência (s) na formatação de políticas públicas (Ball e Bowe, 1992), as razões de ordem externa continuaram presentes no Brasil. Em países de capitalismo semiperiférico (Wallerstein, 2001), como é o caso do Brasil, as políticas públicas são (des) estimuladas e condicionadas por agentes externos. Não raros são os casos em que os elaboradores de políticas públicas têm atitudes e apresentam políticas ainda mais rigorosas do que o recomendado por atores externos, como acontece com as organizações internacionais, a exemplo do Banco Mundial. Autoridades nacionais (policymakers) imaginam que a adoção de recomendações de organismos multilaterais e de governos dos países centrais geraria, supostamente, confiança e credibilidade no país (confidence building), inserção internacional, e promessa de continuidade de inversões estrangeiras ${ }^{7}$. Bresser-Pereira (2001), economista que dirigiu o Ministério da Administração Federal e Reforma do Estado (MARE), sob a presidência de FHC, em contundente crítica, reconhece a incompetência de autoridades governamentais e sua subordinação às elites (financeiras) estrangeiras:

o fracasso em estabilizar e retomar o crescimento econômico após a crise da dívida na América Latina, foi atribuído à determinação incompetente de 
políticas macroeconômicas e a uma estratégia de "construção da confiança", que subordinaram a política às instituições oficiais internacionais e à comunidade financeira (p. 165).

Especificamente a respeito da Educação Superior no Brasil, o Banco Mundial publicou o Relatório 19392-BR - Brazil: Higher Education Sector Study, em 30 de junho de 2000. A seção 3 teve o sugestivo título de Strategies and Recommendations for Higher Education in Brazil. O relatório "Brazil - Higher Education Sector Study", do Banco Mundial, observa que existe pouca oferta de cursos de graduação noturnos (p. 5), que os estudantes universitários provêm dos extratos mais aquinhoados da população (p. 7), e que o vestibular não é um meio democrático de recrutamento, porque os cursos preparatórios para o vestibular são caros, as provas privilegiam a memorização, e os locais de realização dos exames ficam nos centros metropolitanos - longe das grandes populações do interior (p. 12).

Nesse mesmo relatório, o Banco Mundial demonstrou simpatia pelos cursos sequenciais, pela flexibilização dos currículos, pela instituição da acreditação e avaliação - Exame Nacional de Cursos (ENC - "Provão"), e pelo comitê de avaliadores e estatísticas do INEP (p. 17). Ademais, o documento do Banco Mundial teve referência no HEFCE (Higher Education Funding Council for England) como exemplo de financiamento por intermédio de um fundo para a Educação Superior (p. 37), sugerindo o fim da gratuidade na Educação Superior pública e conectando isto a uma maior autonomia para as universidades: "a autonomia acadêmica deveria ser elevada de acordo a uma maior descentralização (diversificação) do sistema de gerência de recursos" (p. 38).

O documento do Banco Mundial procura, sofisticamente, provar que as instituições particulares assistem mais a seus estudantes $(29,14 \%)$ do que as universidades públicas $(10,25 \%$ a $13,55 \%)$ (p. 42). Todavia, a ajuda que as IES privadas fornecem aos alunos se circunscreve a descontos em suas mensalidades; já as IEs públicas, nesse quesito, estariam apoiando com a gratuidade à totalidade de seus alunos. Além do mais, as bolsas de iniciação científica, ensino e extensão, majoritariamente financiadas por agências de fomento ou com recursos próprios, são oferecidas em IES públicas.

A seção 3 do relatório do Banco Mundial está reservada às "Estratégias e Recomendações para a Educação Superior no Brasil”. Percebem-se similaridades e proximidades entre o documento publicado pelo Banco Mundial, o Anteprojeto de Lei de Reforma Universitária e o Documento II do MEC, "reafirmando princípios e consolidando diretrizes na Reforma da Educação". O quadro 1 apresenta um resumo das constatações/sugestões presentes no relatório do Banco Mundial e nas políticas públicas encetadas/ adotadas pelo Governo Lula, demonstrando semelhanças nas diretrizes do Banco Mundial e as políticas públicas para a Educação Superior encetadas/adotadas pelo Governo Lula. 
Quadro 1 - Comparativo do relatório do Banco Mundial e das políticas universitárias do Governo Lula.

\begin{tabular}{|c|c|}
\hline Relatório do Banco Mundial & Políticas universitárias do Governo Lula \\
\hline $\begin{array}{l}\text { Melhoria no acesso (improving access) } \\
\text { por intermédio da diversificação da } \\
\text { oferta de cursos noturnos, da educação } \\
\text { a distância, e do fornecimento de crédito } \\
\text { aos estudantes pobres (p. 46). }\end{array}$ & $\begin{array}{l}\text { Incentivo à educação a distância (Ex. UAB- } \\
\text { Universidade Aberta do Brasil), PROUNI, } \\
\text { cotas, ensino noturno, criação dos IFET, } \\
\text { maior oferta de vagas nas universidades } \\
\text { públicas e a interiorização da Educação } \\
\text { Superior. Durante o Governo Lula (desde } \\
2003 \text { ), e até o momento, foram criadas } \\
14 \text { novas universidades federais, e houve } \\
\text { um aumento da oferta em universidades } \\
\text { federais de } 109,2 \text { mil, em } 2003 \text {, para } 222,4 \\
\text { mil, em } 2010 \text { (MEC, } 26 \text { novembro } 2010 \text { ), e } \\
\text { de próximo a 1.400.000 vagas na esfera } \\
\text { privada (MEC-INEP, 2010). }\end{array}$ \\
\hline $\begin{array}{l}\text { Melhoria da qualidade (improving quality) } \\
\text { através de mecanismos de avaliação } \\
\text { (p. 47). }\end{array}$ & $\begin{array}{l}\text { Novo modelo de avaliação (CONAES-ENADE- } \\
\text { SINAES-IGC: Índice Geral de Cursos) e apoio } \\
\text { ao setor de estatísticas do INEP. }\end{array}$ \\
\hline $\begin{array}{l}\text { Melhoria da relevância (improving } \\
\text { relevance) através de maior flexibilidade } \\
\text { curricular e do atendimento da demanda } \\
\text { de empregadores (mercado de trabalho), } \\
\text { das necessidades locais/regionais, e das } \\
\text { necessidades do consumidor } \\
\text {-estudante- (p. 47) }\end{array}$ & $\begin{array}{l}\text { Os termos presentes (no Relatório } \\
\text { do Banco Mundial) assemelham-se à } \\
\text { terminologia dos documentos oficiais } \\
\text { brasileiros. O anteprojeto Lei de Reforma } \\
\text { Universitária procura atender às questões } \\
\text { de desenvolvimento, demandas locais } \\
\text { e regionais, e propõe os conselhos } \\
\text { comunitários. }\end{array}$ \\
\hline $\begin{array}{l}\text { Melhoria da eficiência (improving } \\
\text { efficiency) por intermédio do mecanismo } \\
\text { de aliar a expansão do sistema à diminuição } \\
\text { de recursos, pela possibilidade de dispor } \\
\text { do seu patrimônio, pela maior autonomia } \\
\text { das universidades, pela criação de fundos } \\
\text { e pelo acompanhamento e prestação de } \\
\text { contas (accountability), tendo por base } \\
\text { um plano de desenvolvimento estratégico } \\
\text { de cinco anos que, por sua vez, deve ser } \\
\text { fundamentado nos objetivos nacionais } \\
\text { traçados pelo governo federal (p. 48). }\end{array}$ & $\begin{array}{l}\text { Destinação de verbas do MEC para as } \\
\text { IFES (Brasil, 2007),* maior autonomia } \\
\text { universitária, e a instituição do PDI (Plano } \\
\text { de Desenvolvimento Institucional). Novo } \\
\text { modelo curricular com a Universidade } \\
\text { Nova e REUNI. (Lima, Azevedo e Catani, } \\
\text { 2008). }\end{array}$ \\
\hline
\end{tabular}

*Art. 3, do Decreto 6.096/2007: “O Ministério da Educação destinará ao Programa recursos financeiros, que serão reservados a cada universidade federal, na medida da elaboração e apresentação dos respectivos planos de reestruturação, a fim de suportar as despesas decorrentes das iniciativas propostas" (Brasil, 2007). 
Não é ocioso dizer que se deve estar atento às soluções sugeridas pelo Banco Mundial, pois, apesar de muitas propostas coincidirem com o anseio do movimento de democratização da Educação Superior, as recomendações embutem mecanismos que pervertem a natureza pública das instituições universitárias. Em vez de solidariedade e estímulo ao bem comum e social, como um "cavalo de Tróia", invariavelmente, as condicionalidades do Banco Mundial entranham doses maiores de competição e mercadorização.

Pelas características da reforma proposta, e das recomendações do Banco Mundial, constata-se que o Governo Lula (2003-2010) executou uma segunda geração de reforma universitária, procurando corrigir exageros e erros da primeira (de FHC), buscando: a) incrementar o acesso à Educação Superior através de uma maior oferta de cursos por meio da interiorização de campi, cursos noturnos, educação a distância, PROUNI e FIES; b) reformatar a avaliação e a acreditação; c) estimular o reconhecimento da relevância social e econômica; d) fornecer maior eficiência ao sistema de Educação Superior ("fazer mais com menos").

O segundo mandato de Lula (2007-2010) mostrou-se muito mais inclusivo e, a despeito das restritivas recomendações do Banco Mundial, conforme dados do Ministério da Educação (MEC, 26, nov, 2010), foram criadas 14 novas universidades federais ${ }^{8}$ em todo o País, gerando uma maior oferta de vagas públicas: "eram 109,2 mil em 2003 e chegaram a 222,4 mil em 2010" (MEC, 26, nov, 2010).

De acordo com o Censo da Educação Superior 2010 (MEC-INEP, 2010), houve aumento da população estudantil no ensino de graduação presencial durante o Governo Lula. A esfera pública respondeu com um aumento de $51,3 \%$ na oferta, passando de 1.085 .977 matrículas em 2002, a 1.643.298 registros de alunos em 2010. O setor privado de ensino superior teve crescimento de $94,5 \%$ no mesmo periodo (2002 a 2010). Em números absolutos, passou de 2.434.650 estudantes a 4.736.001, isto é, 2.301.351 alunos mais, ou um contingente superior ao somatório de matrículas nos sistemas federais, estaduais e municipais públicos (1.643.298 estudantes). Outro dado a ser notado é o vertiginoso aumento da oferta de Educação Superior a distância. De acordo com o mesmo levantamento estatístico (MEC-INEP, 2010), 930.179 alunos estavam matriculados em IES na modalidade a distância, sendo que, em 2002, eram somente 40.714 estudantes, o que significa um salto de $2.184 \%$. Esta expansão na EaD ocorreu majoritariamente pela oferta privada, reforçando a tendência de mercadorização e transnacionalização da Educação Superior no Brasil (Azevedo, 2015a).

A internacionalização da Educação Superior recebeu especial atenção no Governo Lula ${ }^{9}$ com, por exemplo, a criação do Instituto Mercosul de Estudos Avançados (IMEA) em 2007, da Universidade Federal da Integração Latino-Americana (UNILA) em 2010, e da Universidade da Integração Internacional da Lusofonia Afro-Brasileira (UNILAB) em 2010. Em seguida, no governo de Dilma Rousseff (2011-2016), foi criado em 2011 o Programa Ciências sem Fronteiras (CsF), que, inserido no Plano de Aceleração do Crescimento (PAC), foi a marca proeminente de seu governo nas políticas para a Educação Superior, e para a promoção da Ciência, da Tecnologia e da Inovação (C, T \& I). De acordo com Morosini (2011): 
a Política Nacional de Ciência, Tecnologia e Inovação está sendo direcionada, via Plano de Aceleração do Crescimento -PAC da Ciência- para a expansão e a consolidação de um sistema nacional de C,T\&I; a promoção da inovação tecnológica nas empresas; a pesquisa, o desenvolvimento e a inovação em áreas estratégicas (p. 107).

Não só com o Programa CsF, no Governo Rousseff, o Estado estabeleceu, exercendo seu papel de meta-ator social, a regulação da C,T\&I por intermédio de políticas, programas e agências (CAPES, CNPq e FINEP), priorizando o financiamento de áreas consideradas estratégicas, o que necessariamente afeta o campo acadêmico. O Programa Ciências sem Fronteiras comprova esse sentido regulatório do campo acadêmico pelo Estado, restringindo, aliás, a participação das Ciências Humanas neste Programa (CsF). Azevedo e Catani (2013) notam que

a estratégia de Estado e as políticas públicas para a Educação Superior, e o complexo de C,T\&I, mais recentemente, têm se marcado pelas regulações e sinalizações, para que os atores sociais do campo acadêmico brasileiro convertam os esforços em determinadas áreas das ciências naturais e de formação em tecnologia (p. 282).

O Programa CsF previa a distribuição de 75 mil bolsas de estudos em várias modalidades de mobilidade internacional (Doutorado sanduíche, Doutorado pleno, Pós-doutorado, Graduação sanduíche, Treinamento de especialista no exterior, Jovem cientista de grande talento no Brasil e Pesquisador visitante especial no Brasil), nas seguintes áreas prioritárias: Engenharias e demais áreas tecnológicas; Ciências Exatas e da Terra; Biologia, Ciências Biomédicas e da Saúde; Computação e Tecnologias da Informação; Tecnologia Aeroespacial; Fármacos; Produção Agrícola Sustentável; Petróleo, Gás e Carvão Mineral; Energias Renováveis; Tecnologia Mineral; Biotecnologia; Nanotecnologia e Novos Materiais; Tecnologias de Prevenção e Mitigação de Desastres Naturais; Biodiversidade e Bioprospecção; Ciências do Mar; Indústria Criativa (voltada a produtos e processos para desenvolvimento tecnológico e inovação); Novas Tecnologias de Engenharia Construtiva; Formação de Tecnólogos (Brasil, 15 out. 2012).

Ainda, em relação ao governo de Dilma Rousseff, deve-se registrar o debate sobre as cotas sociais e raciais para o ingresso na Educação Superior pública no Brasil. Em seu primeiro mandato, Rousseff sancionou a Lei de reserva de, no mínimo, 50\% das vagas em universidades federais para estudantes de escolas públicas. Dispõe a Lei $\mathrm{n}^{0} 12.711$, de 29 de agosto de 2012, em seu art. $1^{\circ}$ :

As instituições federais de Educação Superior vinculadas ao Ministério da Educação reservarão, em cada concurso seletivo para ingresso nos cursos de graduação, por curso e turno, no mínimo 50\% (cinquenta por cento) de suas vagas para estudantes que tenham cursado integralmente o ensino médio em escolas públicas (Brasil, 2012). 
O governo de Michel Temer, que era o vice-presidente na chapa com Dilma Rousseff (cujo impeachment também tem sido classificado de golpe parlamentar (Oliveira e Machado, 2019; Jinkings, Doria e Cleto)), promoveu políticas e programas que procuraram reverter certas conquistas sociais nos Governos Lula e Rousseff, sendo o Novo Regime Fiscal (NRF) sua expressão reacionária mais evidente. De acordo com Azevedo (2016a),

trata-se [o NRF] de uma reação às conquistas sociais e, por sua vez, constitucionaliza, por duas décadas, o resultado da luta no campo do poder (Estado), metaforicamente, entre as mãos esquerda e a direita, cujo maior efeito (do $\mathrm{NRF}$ ) é o constrangimento dos gastos e investimentos sociais a cargo da mão esquerda do Estado, incumbida como promotora (potencial) da justiça social. Enfim, o NRF é a expressão, impressa como EC n.95 [Emenda Constitucional], na Carta Maior do País, da vitória (circunstancial) dos representantes dos atores sociais historicamente dominantes no País (financistas e variados caçadores de renda - rent seekers) que estão protegidos pela mão direita do Estado (p. 241).

Além de efeitos (perversos) em todas as áreas sociais, como saúde, habitação, cultura e assistência social, merece atenção analisar as consequências do NRF sobre o financiamento da educação brasileira, principalmente em relação ao cumprimento do Plano Nacional de Educação - PNE 20142024 , criando constrangimentos para a realização de suas vinte metas, com destaque para aquelas que são fundamentais para a garantia com qualidade do direito à educação básica, a democratização do acesso, universalização da alfabetização, ampliação da escolaridade, permanência dos estudantes, redução das desigualdades, inclusão, equidade e a valorização dos profissionais docentes. Resume Azevedo (2016a),

O NRF é um amarrilho constitucional que ata as despesas primárias e os investimentos públicos aos patamares de 2016, ano de acanhada execução orçamentária em razão da crise. Contraditoriamente, o NRF não repercute nos gastos financeiros (controlados pela mão direita do Estado), aqueles destinados ao pagamento de juros e amortizações da dívida pública. O NRF restringe os investimentos que influem no desenvolvimento do País e contingencia as despesas primárias, as que se referem ao financiamento de programas e políticas sociais correntes (de responsabilidade da mão esquerda do Estado) e outras (futuras) que poderiam contribuir para o resgate da dívida social com os cidadãos que mais precisam (p. 256).

Já sob o governo comandado por Jair Bolsonaro, a partir de 2019, entre outras políticas e programas de caráter conservador e privatista, foi apresentado o Programa Institutos e Universidades Empreendedoras e Inovadoras - FUTURE-SE, propondo alternativas privadas de financiamento para a Educação Superior. O FUTURE-SE está em sua quarta versão, sendo que até a terceira versão do PL, havia a previsão de contrato de gestão que seria assinado entre dirigentes das Instituições Federais de Educação Superior (IFES) e de Organizações Sociais (OSs) ${ }^{10}$ e, também, contratos de desempe- 
nho, contendo expectativas de resultados e de cumprimento de metas, a ser contraído entre IFES e a União (Brasil, 2019).

O FUTURE-SE, em essência, significa, sob a batuta do economista Paulo Guedes, titular do Ministério da Economia, a radicalização da reforma gerencialista de Estado que vem sendo executada no Brasil desde os anos 1990. Pode-se deduzir que o FUTURE-SE é parte de um projeto de País em que a provisão de bens públicos, necessários ao bem comum, é relegada em favor de soluções de mercado. Em sua quarta versão, continua persistente seu caráter privatista, conforme o inciso I do Art. $1^{\circ}$ :"I - incentivar fontes privadas adicionais de financiamento para projetos e programas de interesse de universidades e institutos federais"

Mesmo que a mensagem 302, assinada por Bolsonaro e enviada ao Congresso em 26 de maio de 2020, portanto a quarta versão do Programa FUTURE-SE, numerada como Projeto de Lei (PL) no 3076/2020 (Brasil, 02 Jun 2020), declare que o mesmo não compromete o que reza o Art. 207 da Constituição Federal, que trata sobre a Autonomia Universitária, o Programa FUTURE-SE, substantivamente, distorce o que diz o Art. 207 da Carta Magna de 1988, que garante que "as universidades gozam de autonomia didático-científica, administrativa e de gestão financeira e patrimonial, e obedecerão ao princípio de indissociabilidade entre ensino, pesquisa e extensão”. Em contraste ao que declara o Art. 207 da CF de 1988, esta quarta versão é explícita ao desafiar o princípio da autonomia universitária. Prenuncia o Art. 31: "Ato do Poder Executivo regulamentará: I - as medidas necessárias à transparência, fiscalização e controle dos instrumentos previstos nesta Lei (...)" (Brasil, 02 jun 2020).

Vale ainda destacar que a quarta versão do PL nº 3076/2020, inesperadamente, faz um giro retórico e demarca três eixos para o Programa FUTURE-SE, aproximando do vocabulário corrente no Ministério da Ciência, Tecnologia, Inovações e Comunicações, em Instituições de Educação Superior, associações industriais, sociedades científicas, agências de financiamento e fundações de apoio à pesquisa. De acordo com o Art. $4^{\circ}$, "O Programa Future-se divide-se em três eixos: I - pesquisa, desenvolvimento tecnológico e inovação; II - empreendedorismo; e III - internacionalização".

De maneira que tal versão do FUTURE-SE vai se aproximar da linguagem de atores sociais da C,T\&I, a exemplo das agências de fomento nacionais e estaduais (CAPES, CNPq, FINEP e Fundações Estaduais de Apoio à Pesquisa, como a FAPESP), associações científicas (SBPC, ABC, etc.) e do próprio Ministério da Ciência, Tecnologia, Inovações e Comunicações (MCTIC) ${ }^{11}$. Isto pode, por efeito, reforçar a orientação de eleição de áreas prioritárias, como ocorreu com o Programa Ciências sem Fronteiras e de discriminação da grande área de Humanidades e da pesquisa básica, a exemplo, também, do acontecido no Programa de Iniciação Científica e Tecnológica (PIBIC) do CNPq, em 2020, conforme manifestarem-se a Sociedade Brasileira para o Progresso da Ciência (SBPC) e Academia Brasileira de Ciências (ABC), em carta de 29 de abril de 2020, dirigida ao Ministro Marcos Pontes, titular do MCTIC. Mesmo que longa a citação, vale a leitura de um extrato da carta:

Em primeiro lugar, agradecemos a sua intervenção para que modificações fossem feitas na Portaria 1122/2020, motivadas por carta que lhe foi enviada 
por nossas entidades, no dia 26 de março de 2020, apoiada por cerca de 70 sociedades científicas das mais diversas áreas do conhecimento. Dois pontos importantes foram acrescentados à Portaria 1122/2020 pela Portaria 1329, de 27 de março de 2020: 1) Foram também "considerados prioritários, diante de sua característica essencial e transversal, os projetos de pesquisa básica, humanidades e ciências sociais que contribuam para o desenvolvimento das áreas definidas nos incisos I a V do caput”; 2) as prioridades definidas na Portaria passaram a ter caráter orientativo para os órgãos do MCTIC e não de obrigação, como anteriormente estava estabelecido. No entanto, um aspecto essencial das nossas preocupações, já colocado na carta anterior, não foi incorporado à portaria mencionada: a definição de programas prioritários para apoio à pesquisa básica (...). A nosso ver (...), os investimentos em CT\&I nos próximos anos não podem negligenciar o apoio à ciência básica, em paralelo às ações de indução nas áreas tecnológicas e de inovação consideradas prioritárias (...). Essa determinação de aderência às áreas de tecnologias prioritárias afunila a cadeia de formação dos jovens desde o início, ou seja, apenas aqueles que estiverem com projetos atrelados a essas áreas poderão ter uma experiência PIBIC, que é um diferencial reconhecidamente marcante na vida de milhares de jovens que se tornaram pesquisadores nas mais diversas áreas. Além disso, no início da carreira, esses jovens serão levados a desistir de certos temas de pesquisa porque eles não estão vinculados diretamente às áreas de Tecnologias Prioritárias.

Para finalizar, vale destacar que a quarta versão do FUTURE-SE, aceitando o contexto de influência externa (Ball e Bowe, 1992), explicita a importância da internacionalização e assume a governança da Educação Superior por contrato de resultados (boas práticas) a ser aferido por indicadores, algo similar à gestão pública por intermédio de "benchmarking" (Azevedo, 2016b). Prescreve o PL n ${ }^{\circ} 3076 / 2020$ :

Art. $6^{\circ} \mathrm{O}$ contrato de resultado será celebrado entre a universidade ou o instituto federal e a União, por intermédio do Ministério da Educação, e terá como contrapartida a concessão de benefícios por resultado (...). § $1^{\circ} \mathrm{O}$ objeto do contrato de que trata o caput consistirá no estabelecimento de indicadores de resultado para a implementação de ações que abrangerão todos os eixos do Programa Future-se. $\S 2^{\circ}$ Os benefícios por resultado compreendem o recebimento de recursos orçamentários adicionais, consignados pelo Ministério da Educação, e a concessão preferencial de bolsas da Coordenação de Aperfeiçoamento de Pessoal de Nível Superior - Capes às universidades e aos institutos federais participantes do Programa Future-se.

Art. $7^{\circ} \mathrm{O}$ Ministério da Educação e o Ministério da Ciência, Tecnologia, Inovações e Comunicações estabelecerão os indicadores para mensuração do desempenho, relacionados aos eixos do Programa Future-se, de forma a contemplar incrementos de eficiência e economicidade, ouvidos as universidades e os institutos federais. $\S 1^{\circ} \mathrm{O}$ desempenho a que se refere o caput será avaliado conforme disposto em regulamento, sem prejuízo do reconhecimento dos resultados já alcançados pelas instituições que desenvolvem ações nas áreas relacionadas aos eixos do Programa Future-se. $\S 2^{\circ}$ Os indi- 
cadores de resultado serão divulgados por ato do Ministério da Educação. Por fim, pergunta-se, como será tratado o PL n ${ }^{\circ} 3076 / 2020$ pelo Congresso Nacional? Haverá debate com os atores sociais do campo acadêmico? Surgirá uma quinta versão do FUTURE-SE? Qual será o futuro da Educação Superior do Brasil?

\section{Considerações finais}

A Reforma da Educação Superior, como uma política pública para um setor estratégico, implica mudanças e deslocamentos espaciais dos atores sociais no campo universitário, o que significa, também, transformações no relacionamento do campo acadêmico com atores sociais estranhos à vida orgânica da universidade.

Pelo apresentado neste ensaio, pode-se observar a ocorrência de uma paulatina reforma da Educação Superior que se encontra na quarta geração de reformas - inclusive com a mercadorização, transnacionalização da educação desse nível de ensino e uso de instrumentos gerenciais de governança por benchmarking (Azevedo, 2020).

A reforma universitária gerencialista que vem sendo emendada por intermédio de uma série de políticas e programas desde os anos 1990 está inconclusa. Na realidade, estão abertas todas as possibilidades de mudanças, pois a quarta versão do PL 7200/2006, que jamais chegou a ser votada no Congresso Nacional, deve encontrar-se com a quarta versão do PL n ${ }^{0} 3076 / 2020$, que institui o Programa Institutos e Universidades Empreendedoras e Inovadoras - FUTURE-SE. Pergunta-se: qual será o futuro do campo da Educação Superior no Brasil? Haverá influência do "capitalismo de plataforma"? Estará o campo da Educação Superior, catalisado pela COVID -19, em vias de assumir uma espécie "capitalismo acadêmico de plataforma”? (Azevedo, 2020).

Enfim, a Educação Superior no Brasil, compreendida como um campo social, espaço de lutas e contradições, é um setor, ao mesmo tempo, estratégico, para a formação da cultura, para o desenvolvimento em todos os âmbitos e é um direito essencial, que precisa ser universalizado, com maior presença da oferta pública, para o avanço da cidadania e da democracia. A democracia não é, simplesmente, a capacidade de voto (em personalidades previamente indicadas), mas um valor universal, no sentido que inclui as democracias econômica, social, étnico-racial e de gênero. Assim, a democratização da Educação Superior é apenas parte do projeto de democratização de toda(s) a(s) sociedade(s). 
1. Trow (2005) classifica a oferta de Educação Superior em três dimensões: "sistema de elite" quando a cobertura de Educação Superior é inferior a 15\% da população na faixa etária de 18 a 24 anos; "sistema de massa", para matrículas entre 16\% e 50\% neste mesmo grupo populacional; e "sistema de acesso universal ou aberto", acima de 50\% desta mesma corte.

2. De acordo com o Art. 2, do Decreto N. 6.096/2007: "O Programa terá as seguintes diretrizes: I - redução das taxas de evasão, ocupação de vagas ociosas e aumento de vagas de ingresso, especialmente no periodo noturno; II - ampliação da mobilidade estudantil, com a implantação de regimes curriculares e sistemas de títulos que possibilitem a construção de itinerários formativos, mediante o aproveitamento de créditos e a circulação de estudantes entre instituições, cursos e programas de Educação Superior; III - revisão da estrutura acadêmica, com reorganização dos cursos de graduação e atualização de metodologias de ensino-aprendizagem, buscando a constante elevação da qualidade; IV - diversificação das modalidades de graduação, preferencialmente não voltadas à profissionalização precoce e especializada; $\mathrm{V}$ - ampliação de políticas de inclusão e assistência estudantil; e VI - articulação da graduação com a pós-graduação e da Educação Superior com a educação básica (Brasil, 2007).

3. Discussões mais detidas sobre transnacionalização e mercadorização da Educação Superior no Brasil podem ser encontradas em Azevedo (2015a e 2015b).

4. Fernando Collor de Mello, que inaugurou a era de reformas neoliberais no Brasil, renunciou ao mandato presidencial, em 29 de dezembro de 1992, para evitar seu impeachment pelo Congresso Nacional, assumindo o cargo em seu lugar o vice-presidente Itamar Franco (1992-1995), que dirigiu um curto governo de matiz mais próximo ao nacional-desenvolvimentista.

5. Vale notar que os processos de diversificação e diferenciação universitárias, avaliações institucionais e avaliações de larga escala, a exemplo do Exame Nacional do Ensino Médio (Enem), desenvolvidos durante os governos de FHC, tiveram tratamento diferenciados nos governos de Lula, com maior interlocução com os atores sociais do campo da educação, inclusive acadêmicos.

6. O Anteprojeto de Lei do Governo Lula tornou-se o Projeto de Lei ${ }^{\circ} .7200 / 2006$, que teve apensados os PL's 4.212/04 e 4.221/04, de autoria, respectivamente, de Átila Lira (PSDB) e João Matos (PMDB), ambos marcados pela forte tendência de desregulamentação e liberalização.

7. Isto vale para o Brasil e para a Argentina. Mesmo seguindo com rigor as recomendações do FMI e do Banco Mundial, percebeu-se tarde que a suposta "confiança" se dissipou rapidamente - basta, por exemplo, que os agentes internacionais notem que o país não tem capacidade de rolagem de sua dívida (Azevedo, 2001).

8. A expansão de vagas em IES federais apoiou-se no Programa de Apoio a Planos de Reestruturação e Expansão das Universidades Federais (REUNI), que tinha por objetivo "criar condições para a ampliação do acesso e permanência na Educação Superior, no nível de graduação pelo melhor aproveitamento da estrutura física e dos recursos humanos existentes nas universidades federais" (Brasil, 2007, Art. $1^{\circ}$ ).

9. Mas, também, a transnacionalização da Educação Superior, pois muitos grupos estrangeiros fizeram aquisições de participações acionárias (quase sempre, totais ou majoritárias) de grupos empresariais brasileiros mantenedores de Faculdades, Centros Universitários e Universidades (Azevedo, 2020).

10. Surpreendentemente, a proposição de contratos de gestão entre IFES e OSs foi retirada na quarta versão do FUTURE-SE, de acordo com o PL n. 3076/2020 (Brasil, 02 Jun 2020).

11. O parágrafo único do Art. 4o. do PL $n^{0} 3076 / 2020$ demonstra um afastamento do jargão ideológico corrente em setores do MEC, e do próprio ex-ministro da Educação 
Abraham Weintraub, e aproximação com quadros conceituais presentes no MCTIC sob o comando do ministro Marcos Pontes: "As ações desenvolvidas no âmbito dos eixos do Programa Future-se têm o propósito de contribuir para o aprimoramento dos esforços de pesquisa, desenvolvimento e inovação, observadas as políticas nacionais de ciência, tecnologia e inovação e as prioridades temáticas definidas pelo Ministério da Ciência, Tecnologia, Inovações e Comunicações” (Brasil, 02 jun. 2020).

\section{Referências}

Azevedo, Mário L. N. A Universidade Argentina em Tempos Menemistas (1989-1999): reformas, atores sociais e a influência do Banco Mundial. Tese (Doutorado em Educação)-Feusp, São Paulo, 2001.

Azevedo, M. L. N. Transnacionalização e mercadorização da Educação Superior: examinando alguns efeitos colaterais do capitalismo acadêmico (sem riscos) no Brasil - A expansão privado-mercantil. RIESup - Revista Internacional de Educação Superior, v. 1, p. 86-102, 2015a.

Azevedo, M. L. N.. Internacionalização ou transnacionalização da Educação Superior: entre a formação de um campo social global e um mercado de ensino mundializado. Crítica Educativa, v. 1 , p. 56-79, 2015b.

Azevedo, M. L. N.. O Novo Regime Fiscal: a retórica da intransigência, o constrangimento da oferta de bens públicos e o comprometimento do PNE 2014-2024. Tópicos Educacionais, v. 1, p. 234-258, 2016a.

Azevedo, M. L. N.. Educação e Benchmarking: meta-regulação e coordenação de políticas baseadas em indicadores e nas chamadas ‘boas-práticas'. Anais do XXIV Seminário Nacional Universitas/Br, 18 a 20 de Maio de 2016, ISSN 2446-61232016. Universidade Estadual de Maringá: 2016b

Azevedo, M.L.N. A Educação Superior no Brasil em Quatro Gerações de Reformas (1990-2020): mercadorização, internacionalização, transnacionalização, benchmarking e "capitalismo acadêmico de plataforma”. In: CABRAL, CASTRO e MENDES (Orgs.). Políticas Públicas. Natal: EduUFRN, 2020 (no prelo).

Azevedo, M. L. N. DE, \& CATANI, A. M. Educação superior, internacionalização e circulação de idéias: ajustando os termos e desfazendo mitos. Revista Inter Ação, 38(2), 273-291, 2013. https://doi.org/10.5216/ia.v38i2.26103

Ball, Stephen J.; BOWE, Richard. Subject departments and the 'implementation' of National Curriculum policy: an overview of the issues. Journal of Curriculum Studies. Pages 97-115, 09 Jul 1992 doi.org/10.1080/0022027920240201

Bourdieu, Pierre. Os usos sociais da ciência: por uma sociologia clínica do campo científico. Trad. Denice Barbara Catani. São Paulo: Edunesp, 2004.

Bourdieu, Pierre. Razões práticas: sobre a teoria da ação. Trad. Mariza Corrêa. Campinas, SP: Papirus, 1996.

Brasil. [Constituição (1988)]. Constituição da República Federativa do Brasil: promulgada em 5 de outubro de 1988. Extraído de < http://www.planalto.gov.br/ccivil_03/constituicao/constituicao.htm>

Brasil. Ministério da Educação. Reafirmando princípios e consolidando diretrizes da reforma da Educação Superior. Documento II. Brasília: 02 ago. 2004. Disponível em: <www.mec.gov. br>. Acesso em: 15 mar. 2005.

Brasil. Projeto de Lei $n^{\circ}$ 7200/2006 - Anteprojeto de Lei da Reforma Universitária (4ª versão de 12 junho de 2006) Disponível em: <https://www.camara.leg.br/>. Acesso em: 22 mai. 2020.

Brasil. Decreto n 6.096, 24 abr. 2007. Institui o Programa de Apoio a Planos de Reestruturação e Expansão das Universidades Federais - REUNI. Diário Oficial da União, Brasília, 25. abr. 2007.

Brasil. Lei ${ }^{\circ} 12.711$, de 29 de agosto de 2012. Dispõe sobre o Ingresso nas Universidades Federais (Lei de Cotas). Brasília: D.O.U. de 30 ago 2012. 
Brasil. Ciência sem Fronteiras. Ministério da Ciência, Tecnologia e Inovação (MCTI). Disponível em: http://www.cienciasemfronteiras.gov.br/web/csf/home. Acesso em: 15 out. 2012.

Brasil. Projeto de Lei $n^{\circ}$ 3076/2020 - Programa Universidades e Institutos Empreendedores e Inovadores - Future-se (1 ${ }^{\mathrm{a}}$. versão, 16 jul 2019). Extraído de https://www.camara.leg.br/proposicoesWeb/ prop_mostrarintegra?codteor $=1900012$. Acesso em $07 \mathrm{dez} 2019$

Brasil. Projeto de Lei $n^{\circ}$ 3076/2020 - Programa Universidades e Institutos Empreendedores e Inovadores - Future-se ( $4^{\mathrm{a}}$. versão, de 02 jun 2020). Extraído de https://www.camara.leg.br/proposicoesWeb/prop_mostrarintegra?codteor $=1900012$. Acesso em 07 jun 2020

Bresser-Pereira, L.C. Incompetência e Confidence Building: por trás de 20 anos de Quase Estagnação da América Latina. Revista de Economia Política, vol. 21, n. 1 (81), jan-mar/2001.

Catani, A. M; Oliveira, J. F. Educação superior no Brasil: reestruturação e metamorfose das universidades públicas. Petrópolis: Vozes. 2002.

Chauí, Marilena. A universidade pública sob nova perspectiva. In: REUNIÃO ANUAL DA ANPED, 26., 2003, Poços de Caldas, MG. Conferência de abertura. Poços de Caldas, MG: Anped, 2003. Mimeografado.

GRAMSCI, Antonio. Selections from the Prison Notebooks. Edited and translated by Quentin Hoare and Geoffrey Nowell Smith. London: EleBook, 1999.

Jinkings, I; Doria, K.; Cleto, M. (orgs). Por que gritamos golpe? para entender o impeachment e a crise política no Brasil. São Paulo: Boitempo, 2016.

Lima, Licínio C. ; Azevedo, Mário Luiz Neves de; Catani, Afrânio Mendes. O processo de Bolonha, a avaliação da Educação Superior e algumas considerações sobre a Universidade Nova. Avaliação (Campinas) [online], vol. 13, n. 1, p.7-36. ISSN 1982-5765. https://doi.org/10.1590/ S1414-40772008000100002.

Gomes, Alfredo Macedo; MORAES, Karine Numes de. Educação superior no Brasil contemporâneo: transição para um sistema de massa. Educ. Soc., Campinas , v. 33, n. 118, p. 171-190, Mar. 2012 . Available from <http://www.scielo.br/scielo.php?script=sci_arttext\&pi$\mathrm{d}=$ S0101-73302012000100011\&lng=en\&nrm=iso $>$. access on 30 July 2020. https://doi. org/10.1590/S0101-73302012000100011.

MEC. Presidente Lula entrega campi de universidades e institutos federais. 26 Nov. 2010. Brasília: Assessoria de Comunicação Social, MEC. Extraído de <http://portal.mec.gov.br/ultimas-noticias/212-educacao-superior-1690610854/16096-presidente-lula-entrega-campi-de-universidades-e-institutos-federais>

MEC-INEP. Censo da Educação Superior 2010. Brasília: Instituto Nacional de Estudos e Pesquisas Educacionais Anísio Teixeira - INEP. Disponível em: <http://www.inep.gov.br>. Acesso em: 15 mai 2020.

MEC-INEP. Censo da Educação Superior 2018. Brasília: Instituto Nacional de Estudos e Pesquisas Educacionais Anísio Teixeira - INEP. Disponível em: <http://www.inep.gov.br>. Acesso em: 15 mai 2020.

MEC-INEP. Censo da Educação Superior 2003. Brasília: Instituto Nacional de Estudos e Pesquisas Educacionais Anísio Teixeira - INEP. Disponível em: <http://www.inep.gov.br>. Acesso em: 22 ago. 2005.

MEC. Presidente Lula entrega campi de universidades e institutos federais. Extraído de http:// portal.mec.gov.br/ultimas-noticias/212-educacao-superior-1690610854/16096-presidente-lula-entrega-campi-de-universidades-e-institutos-federais. Publicado em 26 nov. 2010.

Morosini, M. C. Internacionalização na produção do conhecimento em IES brasileiras: cooperação internacional tradicional e cooperação internacional horizontal. In: Educação em Revista, Revista do Programa de Pós-gradução em Educação da Faculdade de Educação da UFMG, Belo Horizonte, v. 27, n. 01, p. 93-112, abr. 2011.

Muller, Pierre. Les politiques publiques. 36e. Paris: PUF, 2006.

SBPCE (Sociedade Brasileira para o Progresso da Ciência) e ABC (Academia Brasileira de Ciências). Carta ao Ministro Marcos Pontes. Rio de Janeiro/São Paulo: 19 abr 2020. Extraído de http:// www.anped.org.br/sites/default/files/images/sbpc_29_de_abril.pdf 
Oliveira, D.B.R.; Machado, E.R. Vem pra Rua e MBL no contexto do golpe parlamentar no Brasil. LUTAS SOCIAIS, São Paulo, vol.23 n.42, p.98-108, jan./jun. 2019.

Silva Junior, João dos Reis; Sguissardi, Valdemar. Novas faces da Educação Superior no Brasil: reforma do Estado e mudança na produção. Bragança Paulista, SP: Edusf (Univ. São Francisco), 1999.

Trow, M. Reflections on the Transition from Elite to Mass to Universal Access: Forms and Phases of Higher Education in Modern Societies since WWII. Berkeley: University of California, 2005. Disponível em: < https://escholarship.org/uc/item/96p3s213>

Wallerstein, Immanuel. Capitalismo histórico. Civilização capitalista. Rio de Janeiro: Contraponto, 2001.

Worldbank. Brazil: Higher Education Sector Study. Report $\mathrm{n}^{0} 19392-\mathrm{BR}$. Human Development Department. Latin America and the Caribbean Region. Washington: Worlbank, 2000.

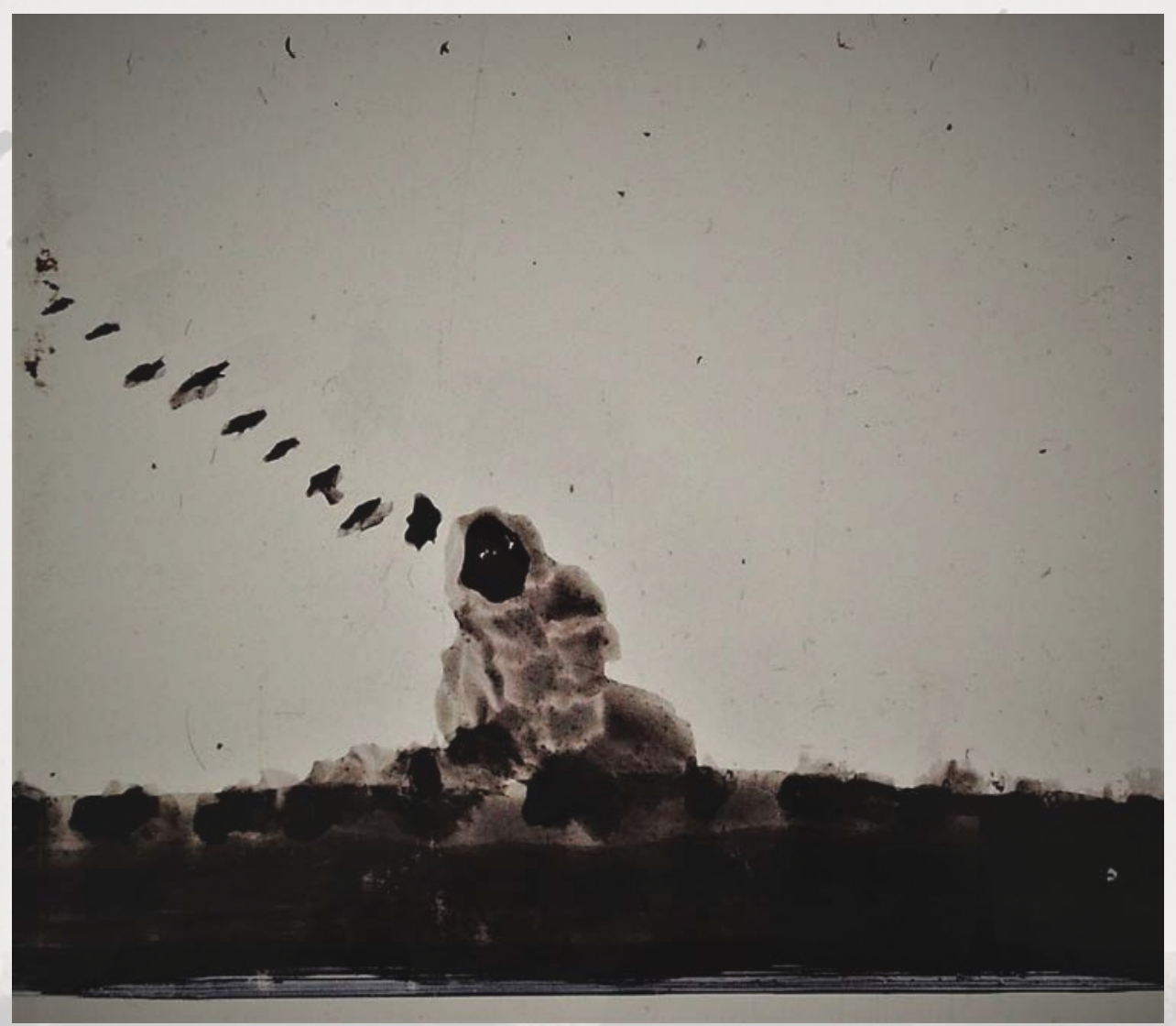

